\title{
Morfógenos Durante el Desarrollo Embrionario de Vertebrados
}

\author{
Morphogens During Embryonic Development of Vertebrates
}

Mariana Rojas",;*; Iskra A. Signore ${ }^{* * * * * *}$ \& Roberto Mejías

ROJAS, M.; SIGNORE, I. A. \& MEJÍAS, R. Morfógenos durante el desarrollo embrionario de vertebrados. Int. J. Morphol., 32(1):319326, 2014.

RESUMEN: Durante el desarrollo embrionario, las células de muchos tejidos se diferencian de acuerdo con la información de posición que se establece por las gradientes de concentración de morfógenos. Estas son moléculas de señalización secretadas en una región restringida de un tejido y se difunden lejos de su fuente para formar una gradiente de concentración. La molécula de un mismo morfógeno actúa generalmente en distintas etapas de desarrollo de un organismo y puede provocar reacciones muy diferentes en las células en función de su historia de diferenciación. Los morfógenos más conocidos son miembros del factor de crecimiento beta (TGFb), Hedgehog (Hh), familias Wnt y los microRNAs.

PALABRAS CLAVE: Morfógenos; Gradiente de morfógenos; Tubo neural; Somitos; Desarrollo embrionario.

\section{INTRODUCCIÓN}

El proceso mediante el cual las células embrionarias dan origen a estructuras ordenadas y coherentes se conoce como formación de patrones, siendo fundamental en esta fase que las células adquieran información posicional. Los patrones del desarrollo se relacionan con la organización espacial del embrión, es decir, las identidades celulares se deben adquirir con la debida orientación espacial (Wolpert, 2009).

Los morfógenos actúan como señales posicionales que controlan el destino celular en el embrión. Este concepto, en el que una gradiente de señalización regula la expresión diferencial de genes de una manera dependiente de la concentración, proporciona una base para la comprensión de muchos procesos de modelado del cuerpo embrionario (Gurdon \& Bourillot, 2001; Tabata \& Takei, 2004; Ashe \& Briscoe, 2006; Wartlick et al., 2009; Kanodia et al., 2011).

El término morfógeno se aplica a una molécula de naturaleza orgánica que es producida y secretada por un grupo de células embrionarias y que puede difundir y actuar a distancia sobre otras células o tejidos (Tabata \& Takei). El morfógeno se une a un receptor de membrana, citoplasmático o nuclear de un grupo de células gatillando en ellas una respuesta celular dependiente de la concentración del morfógeno (Gilbert, 2010). Esto implica que diferentes grupos celulares que se encuentran a distancias distintas del punto de producción del morfógeno van a "detectar" diferentes concentraciones de él. Así, no todos los tejidos que entren en contacto con el morfógeno responderán de igual manera, lo que producirá finalmente una diferenciación celular que es dependiente de la distancia al punto de producción del morfógeno (Wartlick et al., 2009). La concentración del morfógeno en cada punto entrega a las células la información posicional en relación a la fuente de la señal, gatillando respuestas celulares diferentes y correctamente interrelacionadas en el espacio (Gordon et al., 2011) (Fig. 1).

Criterios para reconocer un morfógeno: Idealmente debe ser 1) una molécula de señalización que esté en el lugar correcto y en el momento exacto del desarrollo 2) Debe ser producida por una fuente localizada, 3) Formar un gradiente de concentración dependiente de la distancia, 4) Provocar una respuesta celular directa, es decir que la célula que se encuentra en el gradiente de concentración debe responder

\footnotetext{
Programa de Doctorado en Ciencias Morfológicas. Universidad de La Frontera, Temuco, Chile.

** Programa de Anatomía y Biología del Desarrollo, ICBM, Facultad de Medicina. Universidad de Chile, Santiago, Chile.

*** Instituto de Neurociencias Biomédicas BNI. Universidad de Chile, Santiago, Chile.

***** Unidad de Anatomía Humana, Universidad Mayor, Temuco, Chile.
} 


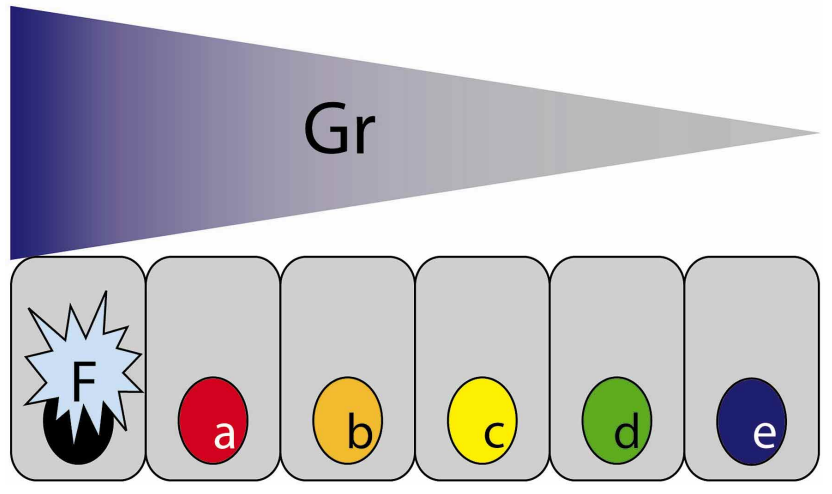

Fig. 1. Un morfógeno es producido desde una fuente localizada (F) y difunde a través de las células para establecer una gradiente. Las células responden a diferentes concentraciones de la señal regulando diferentes sets de genes (rojo, naranjo, amarillo, verde, azul) esto induce diferentes destinos celulares (A, B, C, D, E) a las diferentes distancias de S.

directamente al morfógeno mediante receptores para él. 5) La respuesta debe ser dosis-dependiente, un aumento en el gradiente hará que todas las células experimenten una concentración de morfógeno elevada, y que se cambie su respuesta a un nivel más alto. Del mismo modo, la subexposición al morfógeno debe hacer que las células respondan de manera progresivamente más baja en la escala de respuestas a su disposición. 6) Las células en la ruta del morfógeno deberían mostrar dos o más tipos de respuesta, por ejemplo la expresión de diferentes genes, además de su destino por defecto (Gurdon \& Bourillot).

Modelos para el trasporte de morfógenos. El transporte puede ser por 1) difusión simple a través de los espacios extracelulares; 2) endocitosis a través de las células mediante vesículas endocitócicas 3) proteoglicanos, es así como se ha caracterizado al heparán sulfato (HSPG) como un regulador esencial para la formación de gradientes de morfógenos (Yan \& Lin, 2009). En otros casos, la endocitosis mediada por receptor seguida rápidamente por la degradación ha sido propuesta como una vía de producción de un gradiente neto en la actividad proteica (Wolpert).

El establecimiento de un patrón requiere la interpretación de la información posicional. El biólogo inglés Lewis Wolpert propuso en 1968 un modelo para explicar cómo es posible especificar la información posicional en el embrión. La manera más simple de hacerlo - dice Wolpert es a través de la disminución monótona de la concentración de alguna molécula, es decir, a través de la formación de un gradiente que disminuye con la distancia. La concentración en cada punto entrega a las células la información posicional en relación a la fuente de la señal, gatillando respuestas celulares diferentes y correctamente interrelacionadas en el espacio (Wolpert; Gilbert). Según Wolpert podemos ejemplificar esto con la bandera francesa, ella tiene un patrón simple, un tercio azul, un tercio blanco y un tercio rojo, a lo largo de un eje. Las células deben adquirir información posicional, luego ellas interpretan esta información y se diferencian de acuerdo con sus programas genéticos. Las del lado izquierdo de la línea serán azules, las del tercio medio serán blancas y las del tercio derecho rojas. El modo en que serán interpretados los valores posicionales dependerá de las instrucciones genéticas particularente activas y será influido por su historia de desarrollo. Existe una identidad posicional y una identidad celular pero ambos procesos son desacoplables.

Formación del gradiente: Podemos considerar dos mecanismos simples que permiten crear el gradiente morfogenético. En el primer caso, el morfógeno se produce de manera localizada y difunde, creando un gradiente de concentración (Fig. 2). En el segundo caso, el morfógeno presenta una concentración uniforme contrastada por un inhibidor producido de manera localizada y que presenta una gradiente de concentración. El inhibidor impide la unión del morfógeno a su receptor en la célula de manera proporcional a su concentración en cada punto del espacio. Como resultado, el morfógeno presenta un gradiente de actividad (Fig. 2). En ambos casos, las células reciben una señalización en forma de gradiente que se debe a la presencia del morfógeno (Wolpert; Signore, 2012).

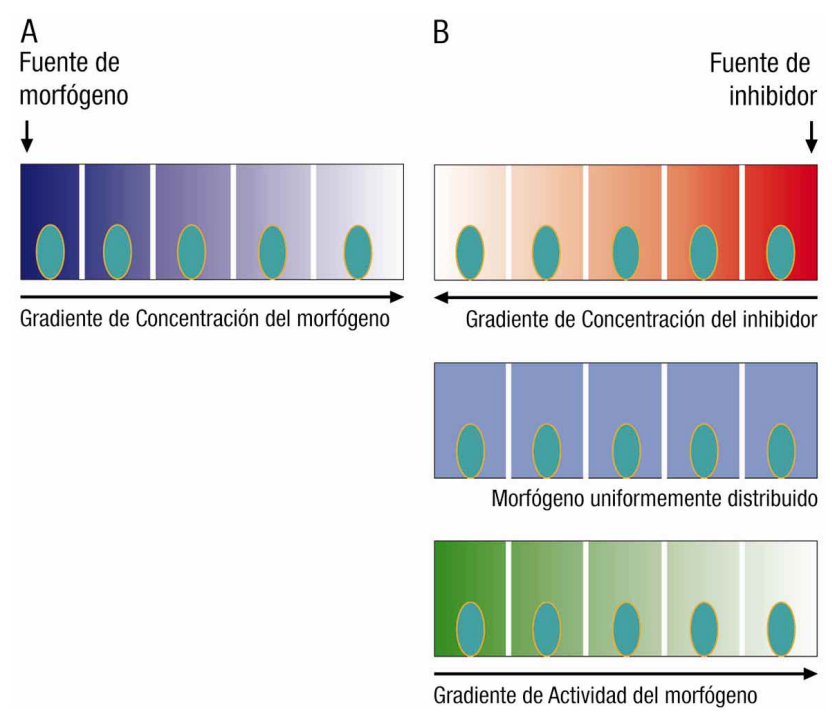

Fig. 2. Mecanismos para crear un gradiente morfogenético A: Fuente de Morfógeno, B: Fuente de inhibidor. 
Concentraciones de los gradientes de morfógenos. Existe poca información directa debido a que estas moléculas parecen ser efectivas a concentraciones muy pequeñas (inferiores a los nanomoles) y que en la mayor parte de los casos no es posible observar la presencia del morfógeno más que por la distribución de su mRNA. Sin embargo, se ha descubierto que en un gran número de casos, el gradiente de un morfógeno se construye mediante la acción de inhibidores. Un ejemplo de este tipo de gradiente se ha encontrado en el desarrollo de Xenopus laevis en relación a la proteína morfogenética de hueso (BMP), perteneciente a la familia de los TGF-b. Existe un antagonismo entre la acción de BMP (ventralizante) y moléculas producidas por el organizador de Spemann (dorsalizante) (Fig. 3). Cuando BMP actúa en el ectodermo, inhibe el destino neural por defecto y promueve la expresión de genes de tipo epidermal. En el mesodermo, BMP promueve en dosis bajas la diferenciación a músculo; en dosis intermedias promueve la formación del riñón y en dosis altas la expresión de genes típicos de las células sanguíneas. El organizador secreta moléculas como Chordin que impiden la acción de BMP en el ectodermo y mesodermo cercanos al organizador (Fig. 3). Chordin no tiene receptores propios sino que actúa uniéndose directamente a BMP, impidiendo que éste interactúe con sus receptores. Las diferentes dosis de BMP, por lo tanto, se obtienen por interacción con sus inhibidores (Wolpert).

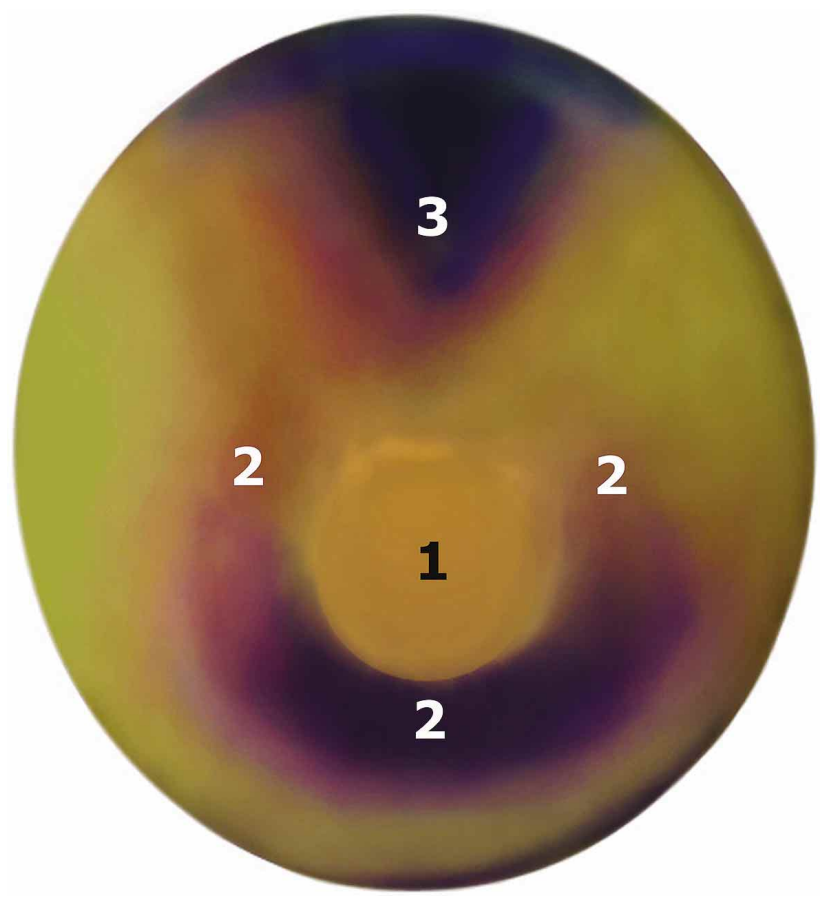

Fig. 3. Dibujo que representa un embrión de Xenopus laevis. En la zona cercana al labio dorsal del blastoporo (1) se observa que la acción de BMP (2) es inhibida por Chordin (3). Modificado de De Robertis, E. Evo-Devo: Variations on Ancestral Themes. Cell, 132:185-95, 2008.
¿Cómo se logra que una población de células tenga respuestas distintas en función de la concentración de un morfógeno? Una posibilidad sería que cada célula presentara umbrales distintos de respuesta. Es decir, cada célula tendría un comportamiento individual binario: responder o no responder a la señal. Las diferencias serían entonces un efecto poblacional y no una característica de la célula individual. Sin embargo, existen experimentos que indican que una célula individual puede desarrollar fenotipos distintos dependiendo de la concentración del morfógeno presente. En estos experimentos se disponen células provenientes del polo animal de una blástula de Xenopus laevis en un arreglo circular alrededor de una esfera embebida con activina. La activina es una molécula tipo TGF-b capaz de inducir tejido mesodérmico a partir del epiblasto. El tipo de mesodermo inducido por la activina depende de la concentración. En particular, a concentraciones bajas de activina se induce la expresión del gen X-brachyury (Xbra), mientras que a dosis altas los genes inducidos son goosecoid (gsc) y eomesodermin (eomes) (Gurdon \& Bourillot). En estos experimentos es posible observar que las mismas poblaciones celulares pueden expresar tanto Xbra cómo gsc, dependiendo de la cantidad de activina a la cual son expuestas, confirmando que la respuesta diferencial al morfógeno es una característica individual de las células.

Morfógenos más conocidos. Aunque en principio cualquier molécula extracelular puede cumplir esta función, la mayoría de los morfógenos se ha relacionado con las familias Wingless (Wnt), TGF-b y Hedgegog (HH).

Morfógenos durante el período somítico. En el desarrollo embrionario es fundamental que de alguna manera las células "reconozcan" su posición y adquieran información posicional. Los somitos son estructuras mesodérmicas que aparecen transitoriamente en el desarrollo embrionario y están ubicadas a ambos lados del tubo neural. Las células que están ubicadas ventromedialmente en el somito se diferenciarán en el cartílago y hueso de la columna vertebral, mientras que la otra parte del somito (dorsal) da lugar a la musculatura estriada y dermis (Aoyama \& Asamoto, 1988). Sin embargo, el mesodermo pre-somítico adquiere su identidad posicional antes de la somitogénesis. Como es conocido, la interpretación de la información posicional y la historia particular del desarrollo de la célula en cuestión actúan en sinergia para la generación de la estructura final pero son procesos distintos. Consecuentemente, no existe una relación simple entre la información posicional y el patrón final: la misma señal y la misma información posicional pueden producir una variedad de formas en tejidos y/o momentos distintos del desarrollo. Esto es un reflejo de las diferencias genéticas y ontogénicas existentes entre distintos grupos celulares. 
En el embrión, se desarrolla una gradiente anteroposterior de factor de crecimiento fibroblástico (FGF), con su punto más elevado en el nodo. Esta gradiente de FGF es formado por las células del nodo que sintetizan mRNA de FGF, el cual es degradado paulatinamente a medida que las células dejan la región en dirección anterior al constituir el mesodermo presomítico. Esto da como resultado una gradiente de proteína FGF traducida y secretada que se mueve contínuamente hacia atrás a medida que el embrión se alarga. El gradiente en el mesodermo disminuye de manera paulatina hasta la posición del último somito formado, lo cual indica que los somitos se constituyen cuando el nivel de FGF llega a un umbral bajo (Aulehla \& Pourquié, 2010). Por el contrario, el ácido retinoico sintetizado y secretado por los somitos origina un gradiente opuesto que antagoniza a FGF. (El ácido retinoico es una pequeña molécula de señalización derivada de la vitamina A). Este morfógeno podría participar en el establecimiento del patrón del embrión mediante la activación de la expresión de genes específicos. Difunde en dirección cefálica desde su sitio de síntesis en los somitos y podría contribuir en la formación del SNC (Deschamps \& Van Nes, 2005; Wolpert). Los cambios en las gradientes de ácido retinoico puede alterar el orden de la expresión de genes Hox y producir malformaciones congénitas. En la naturaleza, un pesticida similar al ácido retinoico originaría ranas deformes (Gilbert). Como ejemplo al tratar ratas gestantes con ácido retinoico durante el $8^{\mathrm{a}}$ día post coito, se pudo observar en los fetos costillas supernumerarias en la región lumbar, además de costillas bífidas y onduladas (López \& Ojeda, 2012).

La formación secuencial de los somitos a lo largo del eje céfalo-caudal está bajo control de multiples gradientes de señalización involucrando: Wnt, FGF, y gradiente de ácido retinoico (AR). Estas vías mostraron una gradiente de distribución de señales dentro del mesodermo somítico de los embriones. Aunque las señales Wnt y FGF mostraron una mayor actividad en el mesodermo posterior no segmentado (mesodermo presomítico) (Figs. 4 y 5). El AR establece una contragradiente con la mayor actividad en los somitos (Figs. 4 y 5). La generación de estas gradientes se basa en los clásicos mecanismos fuente-sumidero (por AR de señalización) y en un mecanismo de desintegraciónde ARN (para señalización de FGF). Se han realizado además numerosos estudios relacionando el ácido retinoico con el patrón segmentario de somitos y con la re-especificación de la vértebra (Kessel, 1992; Houle et al., 2000; Moreno \& Kintner, 2004; Vermot \& Pourquié, 2005). Algunos trabajos revelan la interconexión entre FGF,Wnt, y señales AR para controlar la diferenciación del mesodermo somítico, indicando que altos niveles de señales Wnt y FGF son requeridos para la actividad del reloj de segmentación.

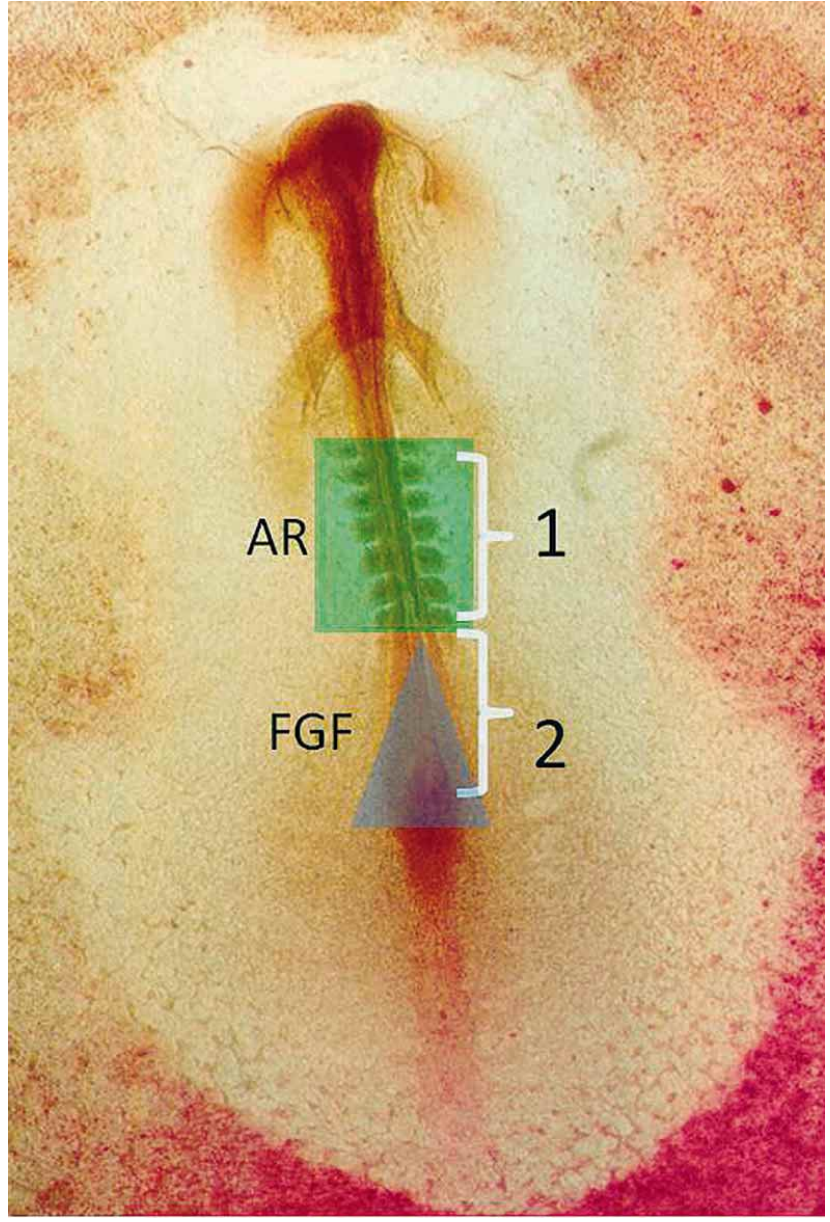

Fig. 4. Embrión de pollo "in toto" de 48 hr de incubación. Se observa somitos y gradiente de ácido retinoico (1). Mesodermo presomítico no segmentado y gradiente FGF (2)

Patrones de expresión de genes que regulan la diferenciación del somito. La proteína SHH secretada por la notocorda y la placa del piso del tubo neural, permite que la parte ventral del somito, forme el esclerotoma y exprese PAX-1. La proteina WNT de la región dorsal del tubo neural activan a PAX-3 que demarca el dermomiotoma. Las proteinas WNT también llevan a la porción dorsal del somito a expresar el gen músculo específico MYF-5 para formar los músculos de la columna vertebral (Sadler).

Los somitos se diferencian en estructuras distintas según su posición a lo largo del eje céfalo caudal. Los más anteriores formarán las vértebras cervicales, y los más posteriores las vértebras torácicas articuladas con costillas. La especificación por posición se produce antes que comience la formación de somitos durante la gastrulación. Si se toma mesodermo somítico no segmentado, desde la región torácica presuntiva del embrión de pollo y se injerta 


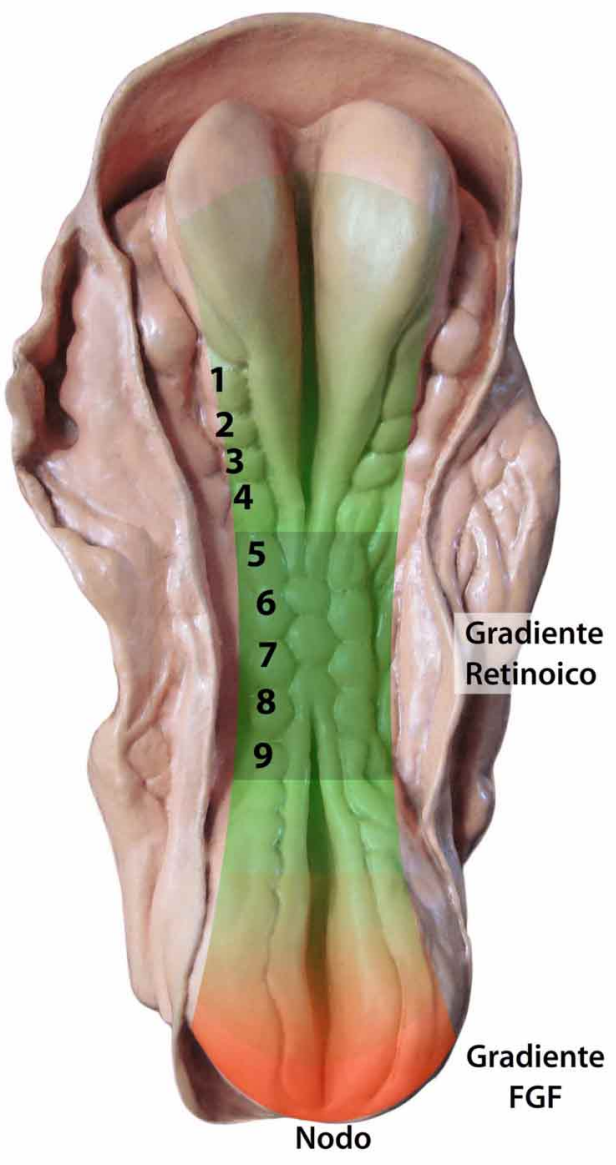

Fig. 5. Modelo que representa un embrión somítico humano. Los somitos están numerados y se encuentran a ambos lados del surco neural. La gradiente de FGF va disminuyendo desde el nodo hasta encontrar su umbral más bajo en el último somito formado. La gradiente de ácido retinoico es muy alta a nivel de los somitos 5-9 y disminuye en dirección cefálica y caudal.

en el mesodermo presuntivo del cuello, este formará vértebras torácicas y costillas en lugar de vértebras cervicales (Wolpert) (Fig 6). El establecimiento del patrón corporal en todos los vertebrados depende de la expresión de genes Hox que especifican la identidad posicional a lo largo del eje (Los genes Hox son miembros de una gran familia de caja homeótica). La identidad posicional de los somitos es especificada por la expresión de los genes Hox a lo largo del eje anteroposterior. La mutación o sobreexpresión de un gen Hox da como resultado defectos localizados en las partes anteriores de las regiones en las que el gen es expresado, y puede causar transformaciones homeóticas (Kessel \& Gruss, 1991; Carapuco et al., 2005).

Morfógenos y Neurogénesis: La proteína SHH secretada por la notocorda gatilla el inicio de la neurogénesis con la formación de la placa neural posteriormente dirige el patrón de neurogénesis transformándose en surco neural. El piso de este surco secreta también SHH. Esto produce un código transcripcional que delinea especialmente distintos dominios progenitores a lo largo del eje dorsal ventral (DV) del tubo neural. Cada dominio generará uno o más subtipos de neuronas, la identidad de los cuales es determinada por la combinación de factores de transcripción expresados por procesos dinámicos que requieren la represión progresiva e inducción de genes a lo largo del eje DV. Como una consecuencia, el tubo neural sufre una ventralización progresiva. En las Figuras 6 y 7 se esquematiza la organización espacial de células progenitoras ventrales de neuronas. Después del cierre del tubo neural, se ordenan a lo largo del eje dorso ventral seis dominios de células progenitoras: placa del piso (PP) además p3, pMN (neuronas motoras), p2, p1 y p0. Cada dominio progenitor genera un subtipo distinto de interneuronas (V0-V3) y moto neuronas (MN) (Fig. 7) (Dessaud et al., 2008).

No obstante que el ligando Sonic hedgehog (Shh) organiza el patrón de diferenciación celular en el tubo neural ventral para los cinco subtipos neuronales, Ribes et al. (2010) demuestran que este modo de acción no es aplicable a la generación de la placa del piso no neuronal(PP)

En embriones de pollo y ratón, la especificación PP implica una respuesta bifásica a la señalización de Shh que controla la expresión dinámica de factores de transcripción. Durante la gastrulación y somitogénesis temprana, la inducción de la PP depende de altos niveles de señalización de Shh. Posteriormente, las posibles células PP se vuelven refractarias a la señalización de Shh, y esto es un requisito para la elaboración de su identidad. Esto lleva a una revisión del modelo de señalización Shh en el tubo

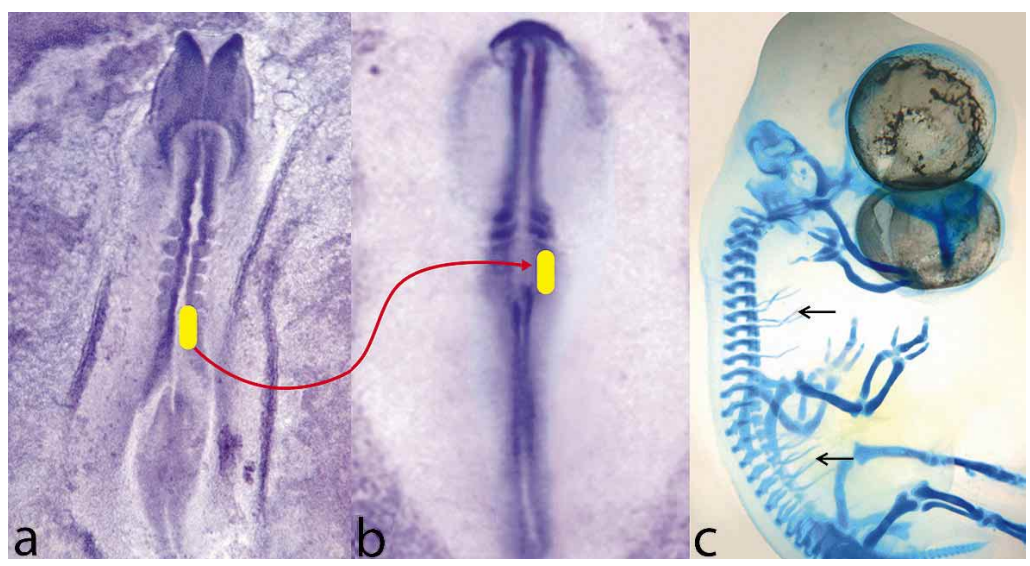

Fig. 6. Diagrama que muestra como el mesoderma presomítico adquiere identidad posicional antes de la formación del somito. Si se toma mesodermo somítico no segmentado, desde la región torácica presuntiva de un embrión de pollo de estadio 10 (a) y se injerta en el mesodermo presuntivo de la región cervical de otro embrión en estadio 8 (b), el esqueleto del embrión receptor a los 8 días formará vértebras torácicas y costillas en lugar de vértebras cervicales (c). 


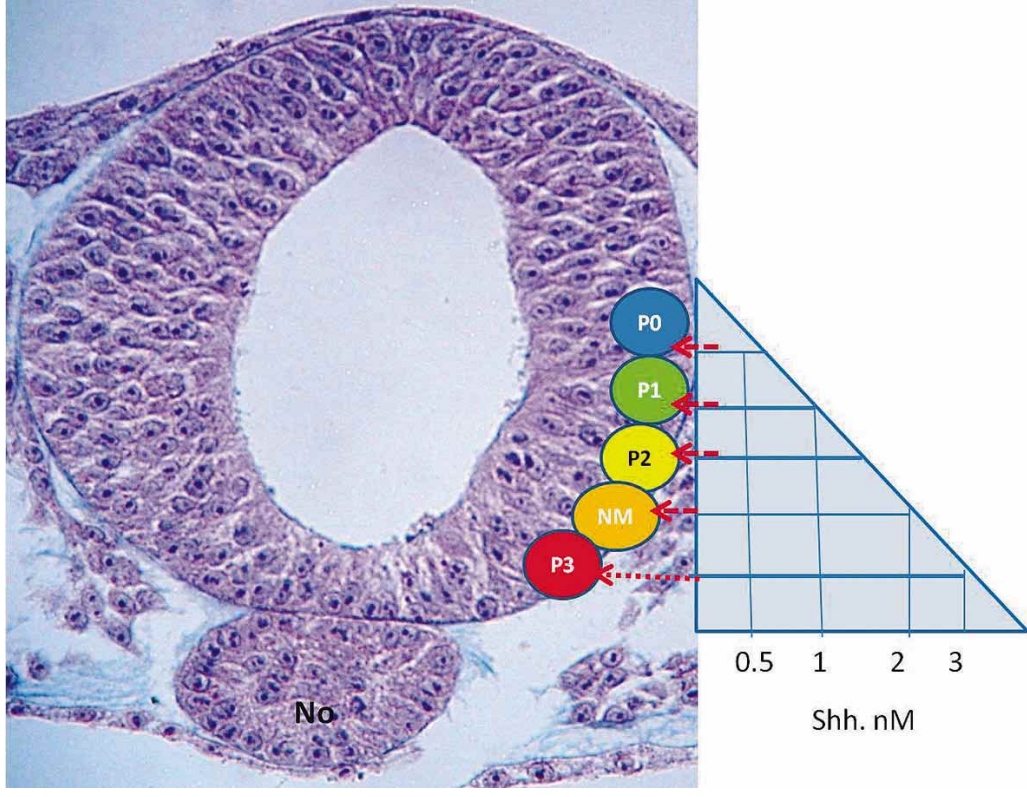

Fig. 7. Morfógenos en las células progenitoras ventrales del tubo neural. Después del cierre del tubo neural, se identifican a lo largo del eje dorso ventral seis dominios de células progenitoras. P3 (rojo), MN (naranjo), P2 (amarillo), P1 (verde), y p0 (azul). En el recuadro se representa las diferentes concentraciones de SHH necesarios para inducir in vitro los distintos subtipos de neuronas. Hematoxilina-Eosina. 400X. Modificado de Briscoe, 2009. EMBO J., 28(5):457-65, 2009.

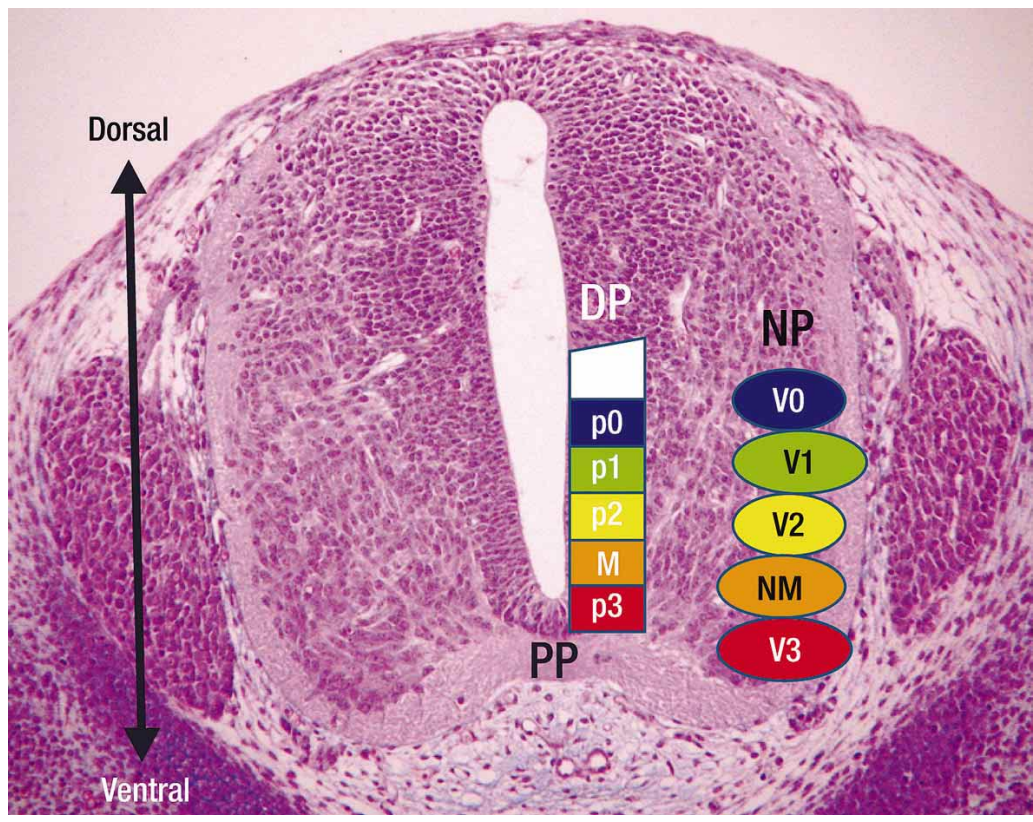

Fig. 8. Tubo Neural de embrión de ratón 12, 5 días. Revistiendo el canal central se observa una capa de células que corresponde al dominio progenitor (DP) La región del tubo neural ventral tiene seis dominios de celulas progenitoras PP, p3, $\mathrm{pMN}, \mathrm{p} 2$, p1, and p0, los cuáles generan en la capa de neuronas post mitóticas (NP) los subtipos interneuronas (V0, V1, V2,V3) y neuronas motoras (MN). La organizacion espacial del dominio de células progenitoras se establece por una gradiente de la proteina SHH (púrpura) secretado por la notocorda y la placa del piso (PP). Tinción Hematoxilina-Eosina. 200X. neural, y da una idea de la dinámica de señalización del morfógeno. Se apoya un sistema común para especificación de señalización de Shh de la PP que concilie el desarrollo de mecanismos de PP en teleósteos y amniotas (Dessaud et al.; Ribes et al.).

Cada dominio progenitor (DP) genera un subtipo distinto de interneuronas ( V0V3) o de moto neuronas (MN). Las células postmitóticas alcanzan su posición final dentro de la médula espinal (Fig. 7) (Dessaud et al.). La emergencia progresiva de perfiles de expresión de genes regulados por $\mathrm{SHH}$ define las identidades de subtipos de neuronas en la médula espinal ventral. La organizacion espacial del dominio de células progenitoras se establece por un gradiente de la proteina SHH secretado por la notocorda y típico de la placa del piso. Por otra parte, los perfiles de expresión de factores transformantes (TFs) Nkx2.b2, Olig2, Nkx6.1, Nkx6.2, Dbx1, Dbx2, Irx3, Pax6 y Pax7 dentro de los progenitores son regulados por la gradiente de la señal SHH. Cada dominio progenitor expresa una única combinación de TFs. Tanto TFs, Olig2 y Nkx2.2 como $\mathrm{SHH}$, diferencian los tres dominios más ventrales (pMN, p3, y PP, respectivamente). La expresión de cada uno de estos marcadores es iniciada en tiempos sucesivos del desarrollo del tubo neural y se extiende a posiciones más dorsales con la aparición de nuevos marcadores. Esta serie de eventos de inducción de genes occurre paralelo a la acumulación y extensión de la gradiente de proteína SHH en el tubo neural ventral (Dessaud et al.).

Morfógenos en el desarrollo de los miembros. Se ha identificado la cresta apical ectodérmica (CAE) y la zona de actividad polarizante (ZPA) como los centros de señales próximodistal (PD) y anteroposterior (AP) en el desarrollo del eje de miembro (Smith et al., 1989; Antonelli et al., 2012). El análisis molecular y genético en el ratón identifica ácido retinoico como señal proximal, FGFs y SHH como las señales instructivas esenciales las cuales son producidas por CAE Y ZPA, respectivamente (Bènazet \& Zeller, 2009). Esto demuestra que las moléculas de un mismo morfógeno 
SHH actúan en diferentes etapas del desarrollo de un embrión, provocando reacciones muy diferentes en las células en función de su historia de diferenciación, como en el caso particular de la diferenciación del tubo neural versus el desarrollo de los miembros.

Otros morfógenos inducen la diversidad biológica al operar de manera dosis dependiente. Hay evidencias recientes que indican que los microRNAs (miRNAs) son ideales para servir la causa de los morfógenos. miRNAs regulan el establecimiento de gradientes de morfógeno, incluyendo TGFb, Wnt y otros factores, actuando sobre su secreción y distribución. miRNAson también críticos en la recepción del morfógeno por parte de las células, estableciendo las respuestas umbral. Además, losmiRNAs contribuyen a las redes de genes que transforman la actividad graduada de un morfógeno en robustas decisiones de destino celular (Inui et al., 2011).

Proyecciones. La adquisición de la información de posición que se establece mediante los gradientes de concentración de morfógenos ocurre en períodos críticos del desarrollo. Los cambios en las gradientes de los morfógenos pueden alterar el orden de la expresión de genes y producir malformaciones congénitas. Las nuevas técnicas de biología molecular y el mayor conocimiento de factores ambientales que se comportan como teratógenos nos permiten reconocer cómo se modifican las estrictas gradientes y moléculas de señalización. Todo esto nos permitirá obtener un mayor conocimiento de las causas y los mecanismos biológicos del desarrollo que se encuentran alterados en los defectos congénitos.

\section{AGRADECIMIENTOS}

Al Dr. Luis Salazar por la revisión de este manuscrito y también a Andrea Godoy y Ana María Hernández diseñadoras gráficas, por realizar los dibujos representativos.

ROJAS, M.; SIGNORE, I. A. \& MEJÍAS, R. Morphogens during embryonic development of vertebrates. Int. J. Morphol., 32(1):319326, 2014.

SUMMARY: During embryonic development, cells in many tissues differ according to the positional information that is set by the concentration of morphogen gradients. These are signaling molecules that are secreted in a restricted region of a tissue and diffuse away from their source forming a concentration gradient. Morphogens generally act at different development stages in an organism and cause different reactions in cells depending on their history of differentiation. The best known example of morphogens are members of growth factor beta (TGF-beta), Hedgehog(Hh), and Wnt families or microRNAs.

KEY WORDS: Morphogen; Gradient morphogens; Neural tube; Somites; Embryonic development.

\section{REFERENCIAS BIBLIOGRÁFICAS}

Antonelli, M.; Rosas, C. \& Rojas, M. Limb Development in Vertebrates. Int. J. Morphol., 30(4):1512-9, 2012.

Aoyama, H. \& Asamoto, K. Determination of somite cells: independence of cell differentiation and morphogenesis. Development, 104(1):15-28, 1988.

Ashe, H. \& Briscoe, J. The interpretation of morphogen gradients. Development, 133(3):385-94, 2006.

Aulehla, A. \& Pourquié, O. Signaling gradients during paraxial mesoderm. Cold Spring Harb. Perspect. Biol., 2(2):a000869, 2010 .

Bènazet, J. D. \& Zeller, R. Vertebrate Limb Development: Moving from Classical Morphogen Gradients to an Integrated 4-Dimensional Patterning System. Cold Spring Harb. Perspect. Biol., 1(4):a001339, 2009.

Carapuco, M.; Nóvoa, A.; Bobola, N. \& Mallo, M. Hox genes specify vertebral types in the presomitic mesoderm. Genes Dev., 19(18):2116-21, 2005.

Deschamps, J. \& van Nes, J. Developmental regulation of the Hox genes during axial morphogenesis in the mouse. Development. 132(13):2931-42, 2005.

Dessaud, E.; McMahon, A. \& Briscoe, J. Pattern formation in the vertebrate neural tube: a sonic hedgehog morphogen-regulated transcriptional network. Development, 135(15):2489-503, 2008 .

Gilbert, S. F. Biología del Desarrollo. $7^{\mathrm{a}}$ ed. Buenos Aires, Médica Panamericana, 2010.

Gordon, P. V.; Sample, C.; Berezhkovskii, A. M.; Muratov, C. B. \&. Shvartsman, S. Y. Local kinetics of morphogen gradients. Proc. Natl. Acad. Sci. U S A, 108(15):6157-62, 2011.

Gurdon, J. B. \& Bourillot, P. Y. Morphogen gradient interpretation. Nature, 413(6858):797-803, 2001. 
Houle, M.; Prinos, P.; Iulianella, A.; Bouchard, N. \& Lohnes, D. Retinoic acid regulation of $\mathrm{Cdx} 1$ : An indirect mechanism for retinoids and vertebral specification. Mol. Cell. Biol., 20(17):6579-86, 2000.

Inui, M.; Montagner, M. \& Piccolo, S. miRNAs and morphogen gradients. Curr. Opin. Cell Biol., 24(2):194-201, 2011.

Kanodia, J. S.; Kim, Y.; Tomer, R.; Khan, Z.; Chung, K.; Storey, J. D.; Lu, H.; Keller, P. J. \& Shvartsman, S. Y. A computational statistics approach for estimating the spatial range of morphogen gradients. Development, 138(22):4867-74, 2011.

Kessel, M. Respecification of vertebral identities by retinoic acid. Development, 115(2):487-501, 1992.

Kessel, M. \& Gruss, P. Homeotic transformations of murine vertebrae and concomitant alteration of Hox codes induced by retinoic acid. Cell, 67(1):89-104, 1991.

Lopez, Y. \& Ojeda, G. Efecto de la administración de ácido retinoico a distintas dosis sobre la morfogénesis ósea de embriones de ratón Mus musculus durante el período embrionario. Tesis para optar al título de matrona, Facultad de Medicina, Santiago, Universidad de Chile, 2012

Moreno, T. A. \& Kintner, C. Regulation of segmental patterning by retinoic acid signaling during Xenopus somitogenesis. Dev. Cell, 6(2):205-18, 2004.

Ribes, V.; Balaskas, N.; Sasai, N.; Cruz, C.; Dessaud, E.; Cayuso, J.; Tozer, S.; Yang, L.; Novitch, B.; Marti, E. \& Briscoe, J. Distinct Sonic Hedgehog signaling dynamics specify floor plate and ventral neuronal progenitors in the vertebrate neural tube. Genes Dev., 24(11):1186-200, 2010.

Sadler, T. W. Langman Embriología Médica. Barcelona, Wolters Kluwer Health, 2010.

Signore, I. A. Guía de Seminarios, Unidad Biología del Desarrollo. Bases Celulares, Genéticas y del Desarrollo Ontogénico. Curso Obstetricia y Puericultura. Facultad de Medicina, Santiago, Universidad de Chile, 2012.

Smith, S.; Pang, K.; Sundin, O.; Wedden, S.; Thaller, C. \& Eichele, G. Molecular approaches to vertebrate limb morphogenesis. Development, 107(Suppl.):121-31, 1989.

Tabata, T. \& Takei, Y. Morphogens, their identification and regulation. Development, 131(4):703-12, 2004.

Vermot, J. \& Pourquié, O. Retinoic acid coordinates somitogenesis and left-right patterning in vertebrate embryos. Nature, 435(7039):215-20, 2005.

Wartlick, O.; Kicheva, A. \& Gonzalez-Gaitan, M. Morphogen gradient formation. Cold Spring Harb. Perspect. Biol., l(3):a001255, 2009.
Wolpert, L. Principios del Desarrollo. $3^{\mathrm{a}}$ ed. Madrid, Médica Panamericana, 2009.

Yan, D. \& Lin, X. Shaping Morphogen Gradients by Proteoglycans. Cold Spring Harb. Perspect. Biol., 1(3):a002493, 2009.

Dirección para correspondencia:

Dra. Mariana Rojas R.

Laboratorio de Embriología Comparada

Programa de Anatomía y Biología del Desarrollo

Facultad de Medicina, ICBM

Universidad de Chile

CHILE

E-mail: dramrojas@hotmail.com

Recibido :21-09-2013

Aceptado:19-12-2013 